\title{
Virology and histopathology in patients with chronic HBV infection in Bulgaria
}

\author{
Donika Krasteva ${ }^{1}$, Radina Ivanova ${ }^{2}$, Cvetelina \\ Marinova ${ }^{1}$, Sonya Dragneva ${ }^{1}$, Nadezhda Zheleva ${ }^{1}$, \\ Evelina Atanasova ${ }^{1}$, Deian Jelev', Krasimir Antonov', \\ Lyudmila Mateva ${ }^{1}$, Zahariy Krastev $^{1}$
}

1. Clinic of Gastroenterology, University Hospital "St. Ivan Rilski”, Medical University, Sofia, Bulgaria;

2. Laboratory of clinical pathology, University Hospital "St. Ivan Rilski", Medical University, Sofia, Bulgaria

\begin{abstract}
The histopathology of hepatitis $B$ is diverse and reflects the natural history of chronic HBV-infection. Liver biopsy is gold standard for assessment of disease-activity and fibrosis. Treatment-decision is based on the assessment of liver disease severity as well as on patient's age, viral load, and $\mathrm{HBeAg}$ status. The relationship between these parameters and liver histopathology is not studied in details. We analysed treatment-naïve patients from single canter: 231 with histologically-proven chronic hepatitis $B(\mathrm{CHB})$ and 104 subjects with clinical, laboratory and ultrasound signs of liver cirrhosis (LC). Viral load and HBV-serology were measured in all cases by real-time PCR and ELISA, respectively. Histological assessment of liver biopsies was performed according to METAVIR. Our results showed that the number of $H B e A g$-positive patient decreases with the increase of the disease activity from $A 0$ to $A 3$ as well as with the increase of the fibrosis stage from F1 to F4. In HBeAg-positive CHB patients both inflammation and fibrosis were more frequently mild or moderate. Severe disease activity (A3) and advanced fibrosis were observed more frequently in HBeAg-negative subjects. HBeAg-positive patients are younger than HBeAg-negative. Such an age difference exists into all separate subgroups
\end{abstract}


of patients with disease activity from $A 0$ to $A 3$ as well as within the subgroups of subjects with different fibrosis stage (F1 to F4).

The mean-age difference between HBeAg-positive and HBeAg-negative patients is about 15 years in all fibrosis subgroups in absence of LC, but in cirrhotics the difference is 10 years. HBeAg-negative patients compared to HBeAg-positive ones were with lower viral load of about $1 \mathrm{log} / \mathrm{mL}$ irrespectively of the grade of the disease activity and the stage of fibrosis. This difference exists even in presence of cirrhosis, although the subjects with cirrhosis were with the lowest viremia both among $\mathrm{HBeAg}$ negative and $\mathrm{HBeAg-positive} \mathrm{subgroups.} \mathrm{This} \mathrm{is} \mathrm{the} \mathrm{largest} \mathrm{and} \mathrm{the} \mathrm{most} \mathrm{detailed} \mathrm{study} \mathrm{in} \mathrm{Bulgaria}$ that compare histologic inflammation and fibrosis with viral load and age in $\mathrm{HBeAg-positive} \mathrm{and}$ HBeAg-negative patients with chronic HBV infection.

Keywords: chronic hepatitis, fibrosis, activity, age, HBV DNA, HBeAg, histopathology

\section{Introduction}

The pathology of hepatitis $B$ is diverse and reflects the natural history of chronic HBV infection which is currently divided into the following five phases: HBeAg-positive chronic infection; HBeAg-positive chronic hepatitis B (CHB); HBeAg-negative chronic infection; HBeAg-negative CHB and HBsAg-negative phase $(1,2)$. The phase characteristic is based on the HBeAg/anti-HBe serological status, viral load, ALT values and presence or absence of liver inflammation and fibrosis. Antiviral treatment is indicated in phase 2 and 4 (2). Several studies conducted in the late 90's confirmed that HBeAg-negative patients compared to HBeAg-positive ones are of older age, have lower viral load and ALT values, but are with more advanced liver fibrosis (3-5). In addition cirrhosis was more frequently found in HBeAg-negative subjects (3-6). All these finding were also confirmed in Bulgarian patients $(7,8)$.

Liver biopsy in subjects with chronic hepatitis B remains the gold standard for evaluating hepatic histopathology. Recently non-invasive methods for assessment of the disease activity and liver fibrosis were approved and accepted by the current guidelines. Thus, in many countries the use of biopsy is limited mainly in select patients based on age, viral load and HBeAg status. The relationship between these clinical and lab parameters and liver histology was still not studied in details.

\section{Aim}

To compare viral load, inflammation and fibrosis in HBeAg-positive and HBeAg-negative Bulgarian patients with chronic HBV infection

\section{Material and methods}

We analyzed treatment-naïve patients with chronic HBV infection that were diagnosed and selected for antiviral treatment in a single clinical center in Bulgaria: 231 with $\mathrm{CHB}$ and 104 with evidence of liver cirrhosis (LC). The diagnosis is based on the classical clinical and laboratory characteristics: physical 
examination, standard laboratory assessment, liver histopathology and abdominal ultrasound. Viral load and HBV serology were measured in all cases by using LightCycler real time polymerase chain reaction (Roche Diagnostics) and commercially available ELISA kits, respectively. Histological assessment of liver biopsies was performed according to METAVIR system. Co-infections with HDV, HCV and HIV were excluded. SPSS was used for statistical analysis of the obtained data.

\section{Results}

231 CHB patients, who had liver biopsies and 104 subjects with liver cirrhosis, were analyzed (table 1 and 2). There were 254 males $(75.8 \%)$. The portion of the HBeAg positive patients was higher in the noncirrhotic patients compared to those with LC ( 26.8 vs $7.7, p<0.0001)$. The level of the HBV DNA in noncirrhotic subjects vs. those with LC was also higher (6.95 $\pm 1.92 \log 10$ vs. $5.77 \pm 1.89 \log 10 \mathrm{IU} / \mathrm{ml} ; p<0.001)$.

Table. 1. Demographics and viral characteristics of patients with chronic HBV infection

\begin{tabular}{|l|l|l|l|}
\hline Parameter & $\begin{array}{l}\text { Non-LC CHB } \\
(n=231)\end{array}$ & $\begin{array}{l}\text { LC } \\
(n=104)\end{array}$ & $P$ \\
\hline Age (Mean \pm SD) & $41.63 \pm 11.41$ & $50.90 \pm 11.74$ & 0.0001 \\
\hline Sex (male/female) & $177 / 54$ & $72 / 32$ & NS \\
\hline HBe Ag positive $(\%)$ & $62(26.8)$ & $8(7.7)$ & 0.0001 \\
\hline HBV DNA, log10 IU/ml & $6.95 \pm 1.92$ & $5.77 \pm 1.89$ & 0.0001 \\
\hline
\end{tabular}

Table 2. Inflammation and fibrosis in Bulgarian patients with chronic hepatitis B

\begin{tabular}{|l|l|l|l|}
\hline Activity grades & Percent & Fibrosis stages & Percent \\
\hline A0 & 7.8 & F1 & 32.5 \\
\hline A1 & 40.7 & F2 & 31.6 \\
\hline A2 & 30.7 & F3 & 22.1 \\
\hline A3 & 20.8 & F4 & 13.9 \\
\hline
\end{tabular}


The distribution of $\mathrm{HBeAg}$-positive $\mathrm{CHB}$ patients according to the grades of activity and stages of fibrosis showed that their number decreased significantly with the increase of inflammation severity from A0 to A3 and with advance of fibrosis from F1 to $\mathrm{F} 4$ (table 3 and 4). The proportions of HBeAg-positive cases with $\mathrm{CHB}$ and no/minimal activity or F4 stage were the lowest. The mean ages of HBeAg-positive patients with $\mathrm{CHB}$ from all subgroups according to the activity grades and fibrosis stage, as well as among the patients with LC, were significantly lower in comparison with the mean ages of HBeAg-negative cases $(p=0.042$ 0.0001), (figure 1 and 2).

Table 3. Distribution of HBeAg positive and negative patients according to the grades of activity and stages of fibrosis

\begin{tabular}{|l|l|l|}
\hline Histopathology of CHB & $\begin{array}{l}\text { HBeAg positive } \\
\text { N (\%) }\end{array}$ & $\begin{array}{l}\text { HBeAg negative } \\
\text { N (\%) }\end{array}$ \\
\hline Activity grades & $7(38.9)$ & $11(61.1)$ \\
\hline A0 (n=18) & $30(31.9)$ & $64(68.1)$ \\
\hline A1 (n=94) & $19(26.8)$ & $52(73.2)$ \\
\hline A2 $(n=71)$ & $6(12.5)$ & $42(87.5)$ \\
\hline A3 $(n=48)$ & & $45(60.0)$ \\
\hline Fibrosis stages & $30(40.0)$ & $56(76.7)$ \\
\hline F1 $(n=75)$ & $17(23.3)$ & $38(74.5)$ \\
\hline F2 $(n=73)$ & $13(25.5)$ & $30(93.8)$ \\
\hline F3 $(n=51)$ & $2(6.3)$ & \\
\hline F4 $(n=32)$ &
\end{tabular}


Table 4. Activity and fibrosis in HBeAg positive and negative patients

\begin{tabular}{|l|l|l|}
\hline Histopathology of CHB & $\begin{array}{l}\text { HBeAg positive } \\
\text { N (\%) }\end{array}$ & $\begin{array}{l}\text { HBeAg negative } \\
\text { N (\%) }\end{array}$ \\
\hline Activity grades & $7(11.3)$ & $11(6.5)$ \\
\hline A0 (n=18) & $30(48.4)$ & $64(37.9)$ \\
\hline A1 (n=94) & $19(30.6)$ & $52(30.8)$ \\
\hline A2 $(n=71)$ & $6(9.7)$ & $42(24.9)$ \\
\hline A3 $(n=48)$ & $62(100)$ & $169(100)$ \\
\hline Total & $30(48.4)$ & $45(26.6)$ \\
\hline Fibrosis stages & $17(27.4)$ & $56(33.1)$ \\
\hline F1 $(n=75)$ & $13(21)$ & $38(22.5)$ \\
\hline F2 $(n=73)$ & $2(3.2)$ & $30(17.8)$ \\
\hline F3 $(n=51)$ & $62(100)$ & $169(100)$ \\
\hline F4 $(n=32)$ & & \\
\hline Total & & \\
\hline
\end{tabular}




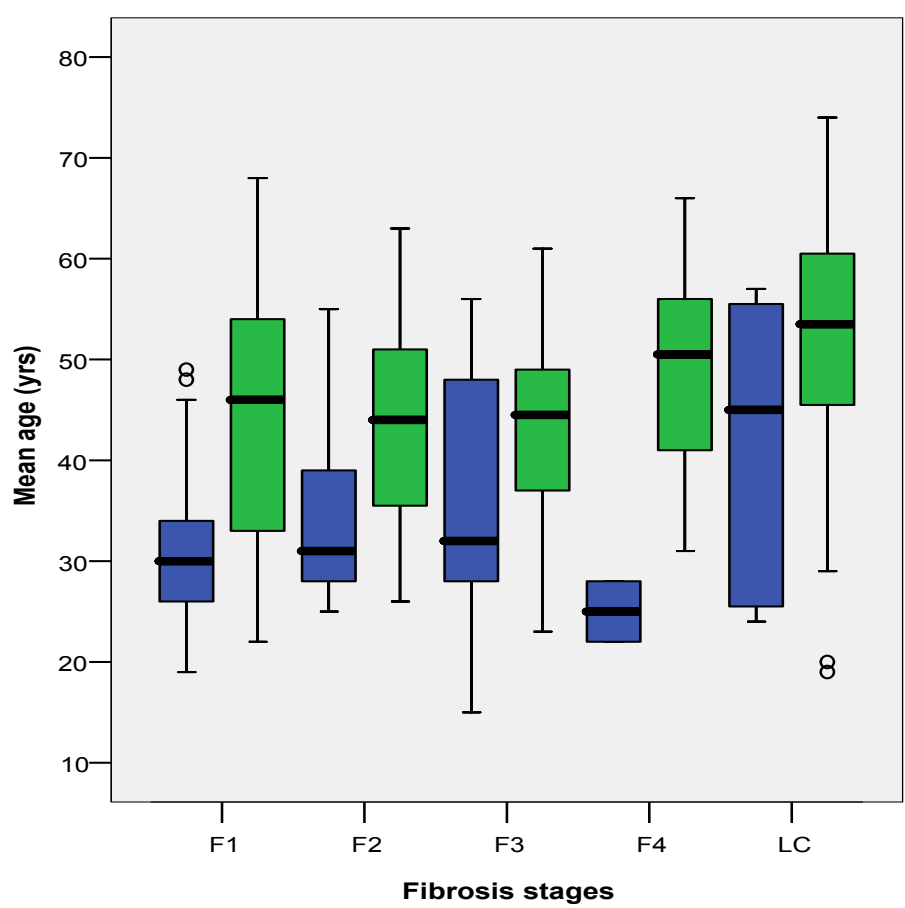

HBeAg

$\square$ positive

$\square$ negative

Figure 1. Mean ages of $\mathrm{HBeAg}$ positive and negative patients with $\mathrm{CHB}$ according to the grades of activity and LC.
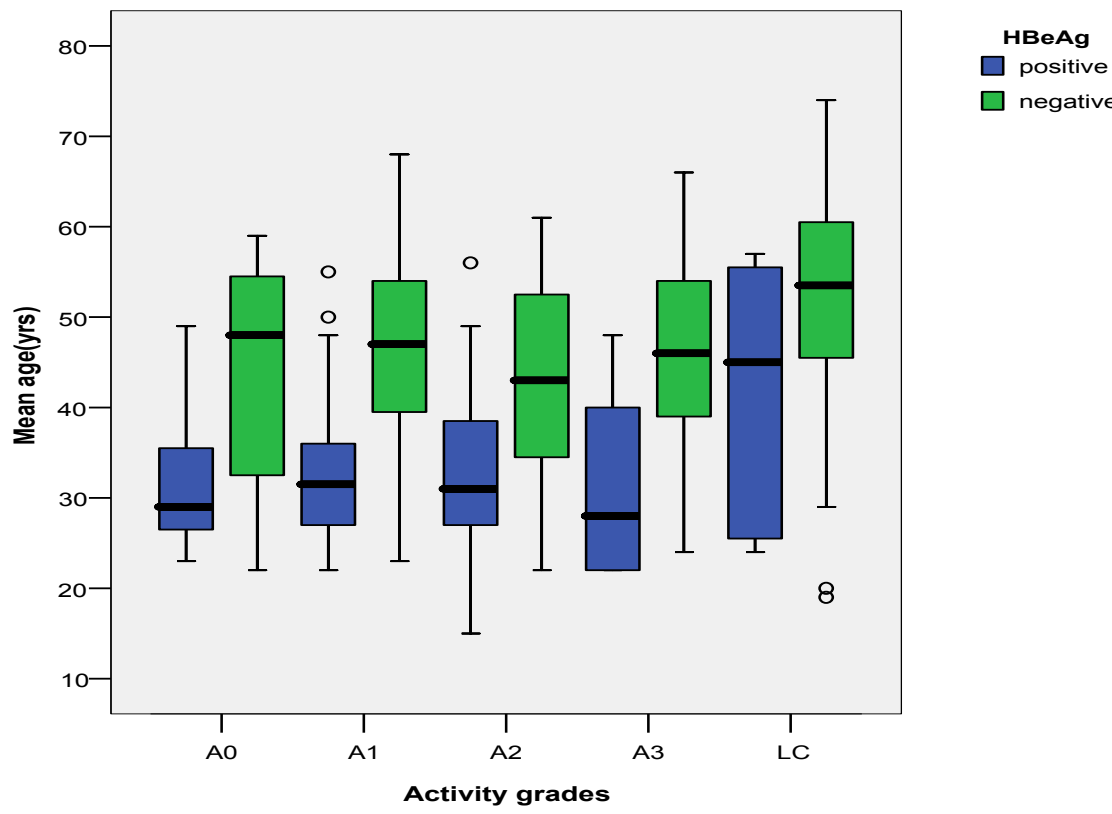

$\square$ negative

Figure 2. Mean ages of $\mathrm{HBeAg}$ positive and negative patients with $\mathrm{CHB}$ according to the stages of fibrosis and LC 
There was a trend for a decrease of the mean serum HBV DNA level among the patients from the subgroups with mild to severe activity grades and also with advance of fibrosis from F1 to F4, (figure 3,4 ). The mean value of HBV DNA was significantly lower in patients with LC compared to the subgroups of subjects with $A 0, A 1, A 2$ or $A 3$ activity grades, respectively $(p=0.001)$. There was also a significant difference between the mean HBV DNA level in the patients with LC in comparison with the same parameter in patients from the subgroups with F1, F2 or F3 stages, respectively $(p=0.001-0.0001)$. The mean value of HBV DNA in patients with $\mathrm{F} 1$ stage was also significantly higher compared to that in patients with $\mathrm{F} 4$ stage/cirrhosis $(p=0.001)$.

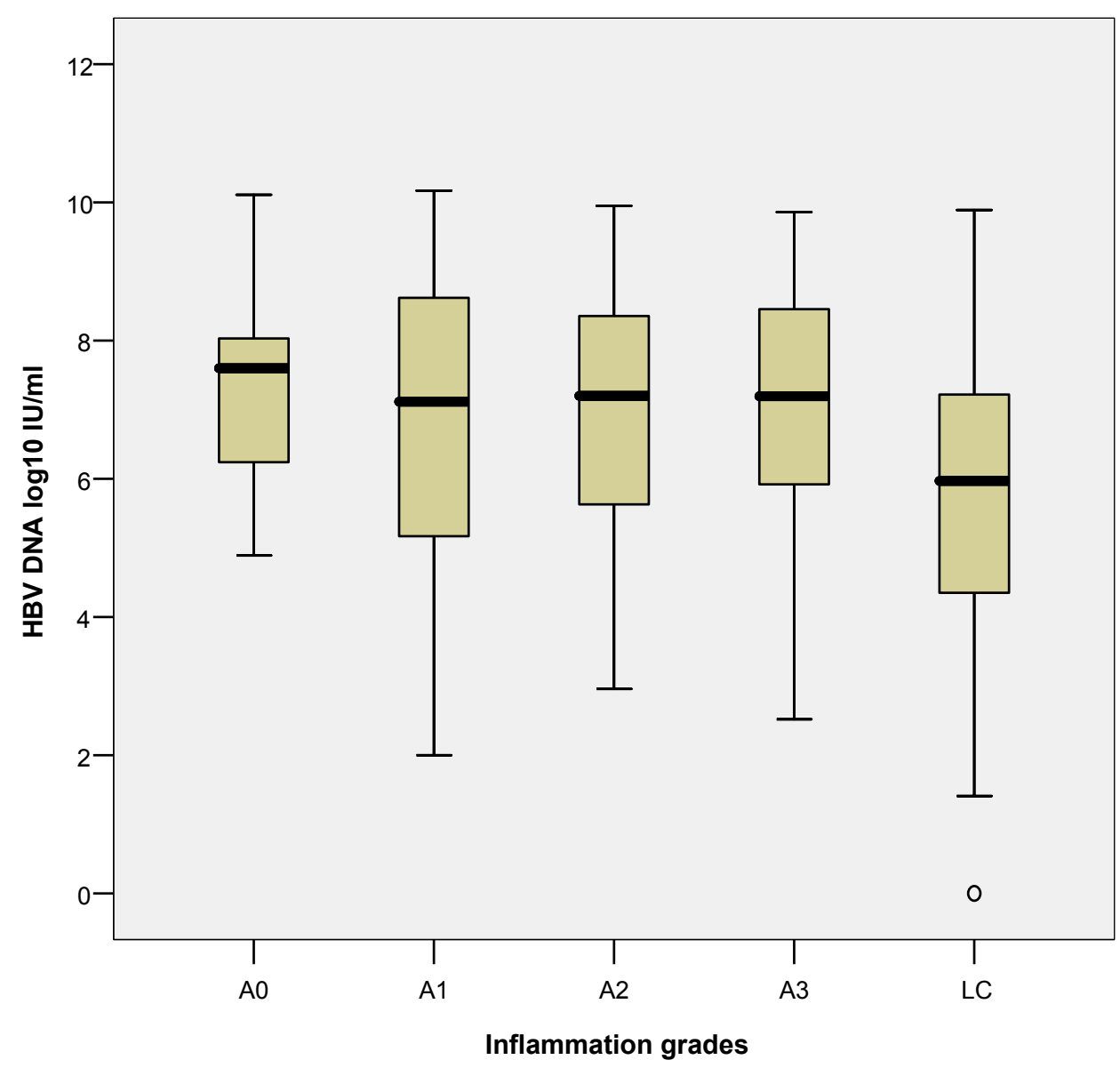

Figure 3. Mean values of HBV DNA load in patients with CHB according to the grades of activity and LC 


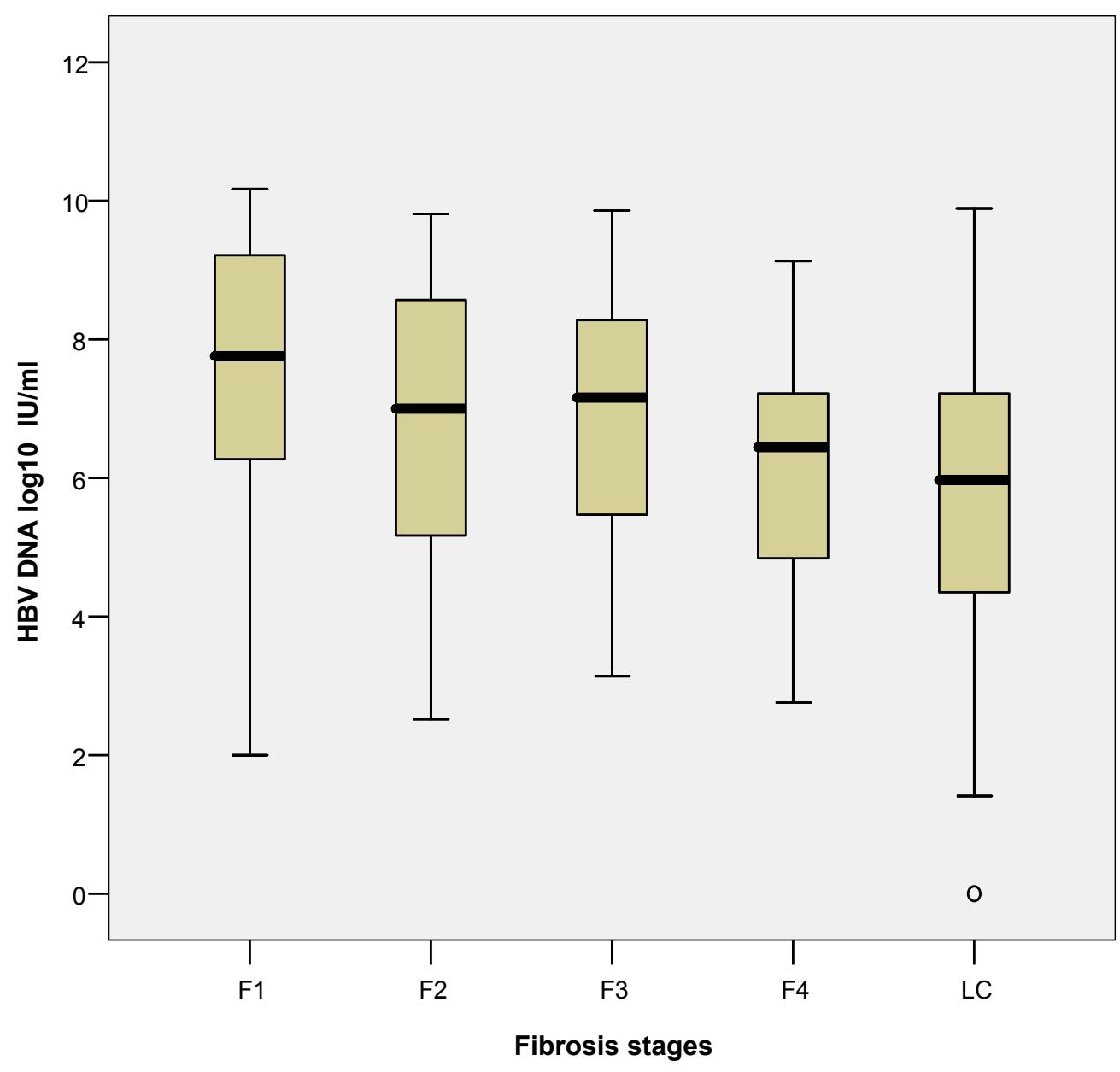

Figure 4. Mean values of HBV DNA load in patients with CHB according to the stages of fibrosis and LC

We also compared the mean values of HBV DNA between the HBeAg-positive and HBeAg-negative patients in their subgroups according to the grades of activity and stages of fibrosis (figure. 5,6 ). We found a trend for higher levels of HBV DNA among HBeAg-positive patients from all subgroups represented activity grades and fibrosis stages. The mean serum HBV DNA level was significantly higher in HBeAg-positive cases with mild $(p=0.001)$ and moderate activity grade $(p=0.042)$ of cases and with $F 1$ $(p=0.0001), F 3(p=0.0001)$ and F4 stage $(p=0.022)$ compared to the mean values of HBV DNA in HBeAgnegative patients. On the opposite, the mean values of HBV DNA in HBeAg-positive patients with LC were significantly lower compared to those of $\mathrm{HBeAg}$ positive patients with $\mathrm{A} 1$ activity grade $(p=0.004), \mathrm{F} 1$ stage $(p=0.011)$ and F3 stage $(p=0.025)$. 


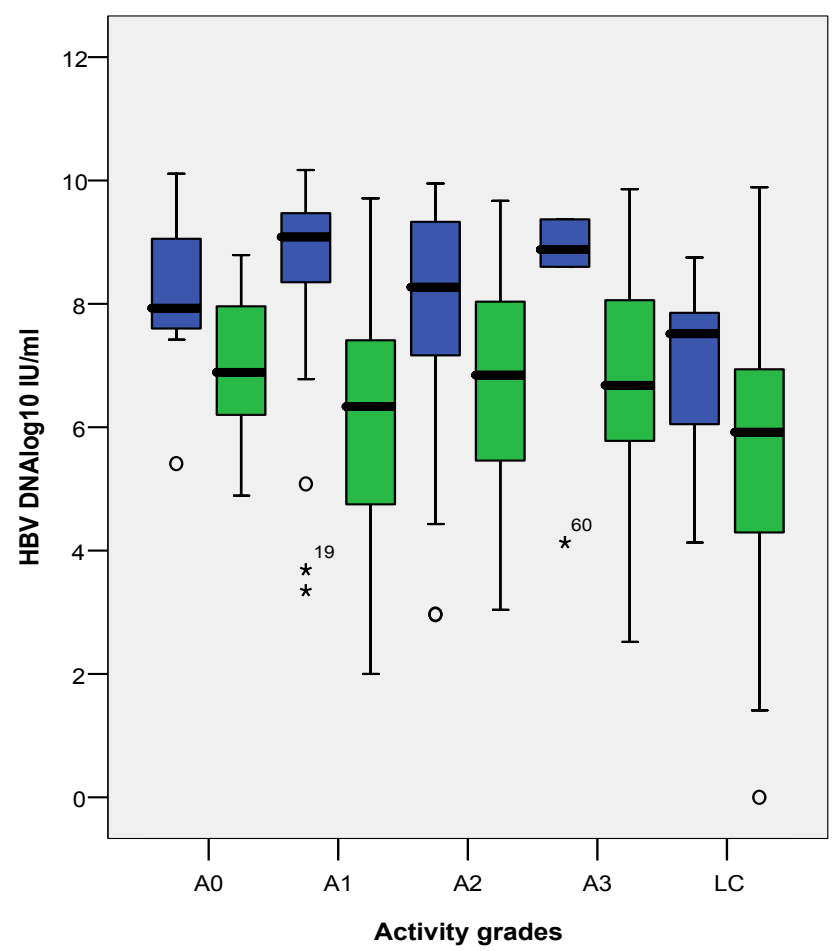

HBeAg

$\square$ positive

$\square$ negative

Figure 5. Mean values of HBV DNA load of HBeAg positive and negative patients with CHB according to the activity grades and LC
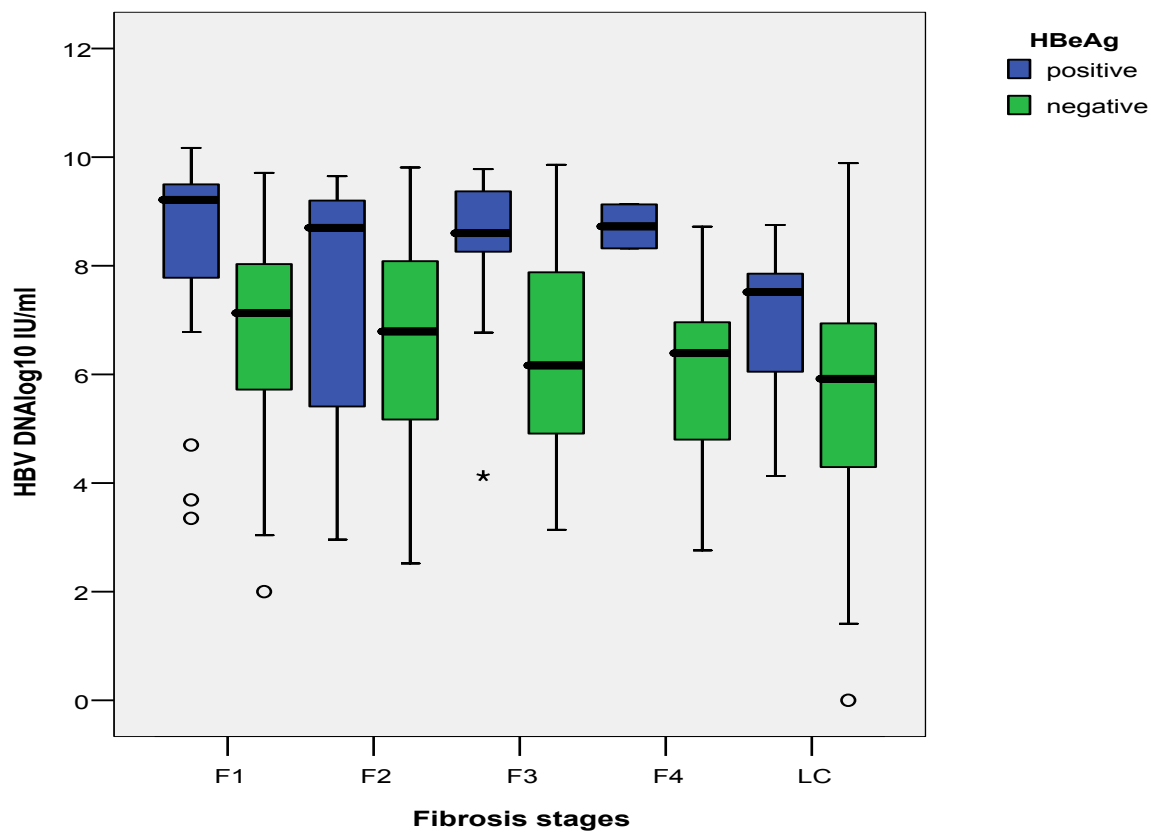

$\square$ negative

Figure 6. Mean values of HBV DNA load of $\mathrm{HBeAg}$ positive and negative patients with CHB according to the fibrosis stages and LC 


\section{Discussion}

The relationship between viral and histopathological parameters is not studied in details in Bulgarian patients with $\mathrm{CHB}$. In our series the number and the proportion of $\mathrm{HBeAg}$ positive patient decreases with the increase of the disease activity from $A 0$ to $A 3$ and with increase of the fibrosis stage from $F 1$ to $F 4$. In $\mathrm{HBeAg}$-positive $\mathrm{CHB}$ hepatic inflammation and fibrosis were more frequently mild or moderate while severe disease activity (A3) and advanced fibrosis were observed more frequently in $\mathrm{HBeAg}$-negative patients. The proportion of $\mathrm{A} 3$ and F4 among HBeAg -negative vs. HBeAg- positive patients were: $24.9 \%$ vs. $9.7 \%$ and $7.8 \%$ vs $3.2 \%$, respectively.

Our data are fully in line with the previous finding that HBeAg-positive patients are younger than HBeAgnegative (3-8). In the present study we demonstrate that such an age difference exist into all separate subgroups of patients with disease activity ranging from $A 0$ to $A 3$ as well as within the subgroups of patients with different fibrosis stage (F1 to F4). A careful analysis of the obtained results revealed that the mean age difference between HBeAg-positive and HBeAg-negative patients is about 15 years in all fibrosis subgroups of subjects in absence of LC, but in the presence of cirrhosis the difference is 10 years. It should be noted that both a sever disease activity and an advanced fibrosis has been found in some $\mathrm{HBeAg}$-positive patients whose age was about 30 years. This clearly suggests that assessment of the histological activity and fibrosis in HBeAg-positive subjects should be considered, although if there is only mild elevation of ALT or relatively low HBV DNA levels (between 2000 and $20000 \mathrm{IU} / \mathrm{mL}$ ), and even if their age is below 40 years. This massage is now very clear in the current EU and US guidelines (2, 9).

In the present study we aimed not only to compare the mean HBV DNA levels of HBeAg-positive and negative patients, but also performed a detailed analysis of viral load according to the grade of disease activity and the stage of fibrosis (figs. 5 and 6). Our results showed that HBeAg-negative patients compared to HBeAg-positive ones were with about $1 \mathrm{log} / \mathrm{mL}$ lower viral load irrespectively of the grade of disease activity and the stage of fibrosis. This difference remained even in presence of cirrhosis, although the subjects with cirrhosis were with the lowest viremia both among HBeAg-negative and HBeAg-positive patient subgroups.

\section{Conclusion}

This is the largest and the most detailed study in Bulgaria that compare histologic inflammation and fibrosis with viral load and age in HBeAg-positive and HBeAg-negative patients with chronic HBV infection. We observed that: (1) the number of $\mathrm{HBeAg}$-positive patient decrease with increase of the disease activity grade and the fibrosis stage. (2) mild inflammation and fibrosis are more frequent in $\mathrm{HBeAg}$-positive CHB-patients, while severe activity and advanced fibrosis are more frequently in $\mathrm{HBeAg}$ negative ones. (3) $\mathrm{HBeAg}$-negative patients compared to HBeAg-positive ones are with $1 \mathrm{log} \mathrm{IU} / \mathrm{mL}$ lower mean HBV DNA level and are average 15 years younger, irrespectively of the activity grade and fibrosis stage. The discussed age-difference is lower (10 years) only in presence of cirrhosis. 


\section{References}

1. Mani H, Kleiner DE. Liver biopsy findings in chronic hepatitis B. Hepatology 2009; 49 (Suppl. 5): S61-71. DOI: 10.1002/hep.22930.

2. European association for the study of the liver (EASL). EASL 2017 Clinical Practice Guidelines on the management of hepatitis $B$ virus infection. J Hepatol. 2017; 67: 370-398. DOI: 10.1016/j.jhep.2017.03.021.

3. Brunetto MR, Oliveri F, Coco B et al., Outcome of anti-HBe positive chronic hepatitis B in alphainterferon treated and untreated patients: a long term cohort study. J Hepatol 2002; 36: 263-270. DOI: https://doi.org/10.1016/S0168-8278(01)00266-5.

4. Di Marco V, Lo lacono O, Camma C, et al., The long -term course of chronic hepatitis B. Hepatology 1999; 30: 257-264. DOI: https://doi.org/10.1002/hep.510300109

5. Papatheodoridis GV, Manesis E, Hadziyannis SJ. The long-term outcome of interferon-a treated and untreated patients with HBeAg-negative chronic hepatitis B. J Hepatol 2001; 34: 306-313. DOI: https://doi.org/10.1016/S0168-8278(00)00094-5.

6. Zarski JP, Marcellin $\mathrm{P}$, Cohard $\mathrm{M}$ et al., Comparison of anti-HBe-positive and $\mathrm{HBe}$-antigen positive chronic hepatitis $B$ in France. J Hepatol 1994; 20: 636 640. DOI: https://doi.org/10.1016/S0168-8278(05)80352-6.

7. Antonov A, Krastev Z. HBeAg-negative chronic hepatitis B.Modern med. 1998; 2: 42-43.

8. Jelev D, Antonov K. Differences between HBeAg-positive and HBeAg-negative chronic hepatitis B. Bulgarian hepato-gastroenterology. 2002; 3: 69-71.

9. Terrault NA, Lok ASF, McMahon BJ, et al., Update on prevention, diagnosis, and treatment of chronic hepatitis B: AASLD 2018 hepatitis B guidance. Hepatology. 2018 Apr;67(4):1560-1599. DOI: 10.1002/hep.29800.

\section{Corresponding author:}

Donika Krasteva,

Clinic of Gastroenterology,

UMHAT "St. Ivan Rilski",

Medical University, Sofia, Bulgaria

Fax.: +3592 8519816

Email: donika.krysteva@gmail.com 